\title{
Symptoms, atopy, and bronchial response to methacholine in parents with asthma and their children
}

\author{
R D CLIFFORD, A PUGSLEY, M RADFORD, AND S T HOLGATE \\ Departments of Medicine and Child Health, University of Southampton
}

SUMmARY We have studied 50 children with one parent with asthma at a mean age of 6.4 years by symptom questionnaire and performed allergy skin testing and measurement of bronchial responsiveness to methacholine in both parent and child in 29-32 cases. Ninety eight per cent of the parents were receiving medication for asthma. Fifty one per cent had visited their doctor and $20 \%$ had taken more than five days off work in the previous 12 months; $12 \%$ had been admitted to hospital during the preceding 10 years. In the children the prevalences of wheeze, shortness of breath, and cough were all about double that found in a general population survey of children of similar age. Atopy was present in $90 \%$ of parents, but the prevalence of atopy among the children was not significantly different from the children in the general population. Eczema and hay fever, however, had high prevalences of $40 \%$ and $24 \%$, respectively. Responsiveness to methacholine (provocation dose achieving $20 \%$ fall in forced expiratory volume in one second $<6.4 \mu \mathrm{mol}$ ) was found in $93 \%$ of parents and $45 \%$ of children, which is compatible with a large increase compared with the general population. All atopic but only $50 \%$ of non-atopic children with symptoms of asthma responded to methacholine.

These findings indicate that children who have one parent with asthma have roughly double the chance of developing clinical features of asthma compared with the general population and suggests that, in these children, a causal interaction occurs between atopy and bronchial hyper-responsiveness.

Bronchial asthma is a disease with a reported current prevalence in adults of $1 \cdot 2-6 \cdot 2 \%$ in the western world. ${ }^{1}$ Recent work in the United Kingdom has shown that prevalence figures of between $10 \%$ and $12 \%$ are more realistic for schoolchildren under the age $10 .^{23}$ The derivation of figures for the prevalence of asthma assumes, however, a precision of diagnosis and definition that does not exist for this disease. ${ }^{4}$ In an attempt to overcome this problem some workers have described prevalence figures for a single symptom, such as recurrent wheeze. ${ }^{3}$

One of the major pathophysiological features of asthma is the presence of enhanced responsiveness of the airways to a wide range of specific and non-specific stimuli-bronchial hyper-reactivity or hyper-responsiveness. Non-specific bronchial responsiveness may be quantified in the laboratory by provocation testing with agents such as histamine, methacholine, and cold air ${ }^{5-7}$ and is closely related to symptomatic bronchial irritability characterised by symptoms of wheeze, cough, dyspnoea, or chest tightness in response to a variety of environmental factors. ${ }^{8}$

A common aetiological factor proposed for asthma in older children and young adults is atopy defined by skin prick testing to common environmental allergens and the presence of associated allergic disease, such as eczema, rhinitis, urticaria, and food allergy. ${ }^{8}$ It has been suggested that atopy may enhance the expression of an independently inherited tendency to develop asthma. ${ }^{9}$ In support of this hypothesis studies have indicated that, in susceptible individuals, environmental exposure to common allergens, such as grass pollen and house dust mite, enhances bronchial responsiveness to histamine and methacholine at the same time as precipitating symptoms of asthma ${ }^{10}$ and that removal from the offending allergens reverses the process. ${ }^{11}$

Several family and twin studies have shown a 
familial component in the aetiology of the atopic illnesses ${ }^{9} 12$ - asthma, eczema, and hay fever. So far, however, there has been no prospective investigation to determine the extent of this relation. In this paper we describe a study involving a cohort of children who had one parent with asthma in which we compared the range of respiratory symptoms with atopic state and measurement of bronchial responsiveness to methacholine.

\section{Patients and methods}

Patients. The original cohort of 100 children, with a family history of asthma, was collected from an antenatal clinic between 1977 and 1979 for a study of respiratory syncytial virus infection and maternal antibody concentrations. ${ }^{14}$ All children in the cohort had a first degree relative with asthma, and in 89 children this consisted of one parent with asthma; the other 11 children were excluded from this study. A further 11 children had been lost to follow up during the previous six years. During January 78 sets of questionnaires were sent out. In March nonspecific bronchial provocation testing and skin tests for atopy were performed on as many parents and children who responded to the questionnaire as possible.

Control subjects. These were taken from a recent survey of Southampton schoolchildren using the same respiratory questionnaire and included 1276 children aged between 6.8 and 7.8 years (mean age $7 \cdot 3$ years). ${ }^{15}$ Of these, 157 selected from different symptom groups were later successfully tested for bronchial response to methacholine and atopy as in the cohort survey. Prevalence figures for atopy and bronchial responsiveness to methacholine were derived by extrapolation from each symptom group tested to the frequency in the general population.

Questionnaires.* Parents were asked to complete two questionnaires, one concerning symptoms in the index child and the other in the patient with asthma. The three questions used to indicate wheeze, dyspnoea, and cough were: 'Has your child ever had attacks of wheezing (by wheezing I mean noisy breathing with a whistling quality coming from the chest not the throat)?'; 'Has your child ever been unexpectedly breathless or more breathless than you would expect after exercise (by breathless I mean out of breath or puffed)?'; and 'Has your child ever seemed to cough more than other children?'. Some

${ }^{*}$ Copies of the questionnaire used can be obtained on application to Dr R Clifford, Medicine 1, Southampton General Hospital, Tremona Road, Southampton. parents answered positively only to the questions enquiring about night or morning cough and these children were also designated as having cough. Detailed information was sought on each symptom, including whether it had occurred in the preceding 12 months, in which case the symptom was coded as 'current'. Further questions were added concerning the existence of hay fever or eczema ('eczema or patches of dry, itchy skin').

The parent's questionnaire was shorter and sought confirmation of diagnosis of asthma in addition to information on severity and provoking factors. The three historical questions used to indicate bronchial irritability in the parents were those shown by Mortagy et al as predictive of bronchial hyper-responsiveness in Southampton adults: ${ }^{16}$ 'Do you ever wake up at night with breathlessness?'; 'When you get up in the morning how does your chest feel: free or tight; if tight how long does it take to become free?'; and 'Do any of the following give you either shortness of breath or wheezing: going from a warm room into a cold room; entering a room where people are smoking; traffic fumes; chemicals-for example, hair spray, bleach, perfumes?'.

Both questionnaires provided for information on current medication.

Measurement of bronchial responsiveness. The method used was that described by Yan et al $^{17}$ and recommended by Woolcock ${ }^{18}$ for epidemiological work. This method was chosen for its simplicity and speed. Methacholine was chosen as the provoking agent because of the absence of side effects, stability in solution, and economy; on a molar basis its potency as a bronchoconstrictor agent is reputed to be similar to histamine. ${ }^{18}$

The methacholine aerosol was delivered from hand held DeVilbis number 40 glass nebulisers. The output of each nebuliser was measured by weighing before and after the same operator squeezed the bulb 10 times on 10 separate occasions. Five nebulisers were chosen with output coefficients of variation of less than $15 \%$. Concentrations were adjusted according to nebuliser output and required dose.

After instruction in the use of a dry wedge bellows spirometer (Vitalograph Ltd, Buckingham, England) the subject's baseline forced expiratory volume in one second $\left(\mathrm{FEV}_{1}\right)$ and forced vital capacity were measured and the highest reproducible value recorded. The bulb of the nebuliser was then squeezed by the operator at the beginning of an inspiration from functional residual capacity to total lung capacity and the subject asked to breath hold for three seconds. After 60 seconds $\mathrm{FEV}_{1}$ was 
measured and the higher value of two measurements that were reproducible within $0 \cdot 2$ litres in adults and $0 \cdot 1$ litres in children was recorded. After an initial inhalation of normal saline subjects were given increasing doses of methacholine from $0.025 \mu \mathrm{mol}$ to $6.4 \mu \mathrm{mol}$. This is equivalent to a concentration range of $0.08 \mathrm{mg} / \mathrm{ml}$ to $20 \mathrm{mg} / \mathrm{ml}$ using the methodology of Cockcroft et al. ${ }^{519}$ Doubling doses were administered to severe or labile adults with asthma and in all children with symptoms of asthma. In the remaining subjects quadrupling doses were used unless a $10 \%$ fall in $\mathrm{FEV}_{1}$ was recorded, in which case they were moved to the slower regimen. The dose given was expressed cumulatively by including previous doses.

The test was continued until either the highest dose had been administered or a greater than $20 \%$ drop in $\mathrm{FEV}_{1}$ from the post-saline measurement had been recorded, in which case the result was scored 'positive'. Any bronchoconstriction caused by the methacholine was then reversed with inhaled salbutamol. The cumulative provocation dose of methacholine required to cause a $20 \%$ fall in $\mathrm{FEV}_{1}$ $\left(\mathrm{PD}_{20}\right.$ methacholine) was calculated from a log dose response curve by linear interpolation. ${ }^{18}$

Skin testing. Saline and histamine controls together with three allergen extracts-Dermatophagoides pteronyssimus, mixed grass pollens, and cat dander (Bencard, Middlesex)-were used for intradermal testing. The skin was pricked through the solution on the anterior aspect of the forearm, using a sterile 25 gauge needle, without drawing blood. Any weals produced by the control solutions of allergen extracts were measured after 10 minutes and the diameters recorded. Those with diameters greater than $3 \mathrm{~mm}$ were scored positive.

Data analysis. Data was coded and stored on an ICL2976 computer. Analyses were performed using the statistical package for social sciences. ${ }^{20} \chi^{2}$ Tests using Yates's correction were used to assess the significance of differences in proportion of symptoms between the cohort and the general population. Fisher's exact test was used to measure the association between atopy and bronchial responsiveness. Where appropriate, $95 \%$ confidence intervals for the difference between proportions have been supplied as recommended by Gardner and Altman. $^{21}$

\section{Results}

Responses. Of the 78 sets of questionnaires posted, 50 were returned completed and 16 were returned with the response 'moved, address unknown', giving a return rate of $81 \%(50 / 62)$. The mean age of the children was 6.4 years. Of the 50 respondents, 35 agreed to attend with their children for skin testing and measurement of bronchial response to methacholine. Three failed to keep their appointment. Thus 32 parents and 32 children were seen for testing. Four parents and three children were excluded from methacholine provocation testing either because their baseline $\mathrm{FEV}_{1}$ was less than $70 \%$ predicted (two parents and two children) or because the subject was unable to perform the procedure (two parents and one child). All 64 parents and children attending the department were skin tested.

Parent's questionnaire. Information was not available on one parent who had died since collection of the cohort. Table 1 shows data on severity of asthma together with the symptoms of bronchial irritability. Thirty nine $(81 \%)$ of 48 parents were receiving medication for asthma but only $25(51 \%)$ had seen their doctor in the previous 12 months. Forty five $(92 \%)$ parents answered positively to one or more of the three symptom questions, with 44 of these experiencing the symptom of wheeze or dyspnoea precipitated by exposure to cold air, chemicals, fumes, or smoke.

Children's questionnaire. Ten children $(20 \%)$ had

Table 1 Morbidity (\%) due to asthma and symptoms of bronchial irritability in the 49 parents

Receiving asthma medication

Visited doctor for asthma in previous 12 months

Hospital admission in previous 10 years

More than five days off work in previous 12 months

Morning tightness $>1$ hour

Nocturnal dyspnoea

Wheeze or dyspnoea with cold air. chemicals. fumes, or smoke 81 51 12 20

Table 2 Prevalence of symptoms in a cohort of 50 children (mean age 6.4 years) with one parent with asthma compared with 1276 children from a general population sample (mean age 7.3 years)

\begin{tabular}{|c|c|c|c|c|}
\hline \multirow[t]{2}{*}{ Symptoms } & \multicolumn{2}{|c|}{$\begin{array}{l}\text { Current prevalence } \\
(\%)\end{array}$} & \multicolumn{2}{|c|}{$\begin{array}{l}\text { Cumulative prevalence } \\
(\%)\end{array}$} \\
\hline & Cohort & Control & Cohort & Control \\
\hline Wheeze & 22 & $11 \cdot 9$ & 28 & $19 \cdot 4$ \\
\hline Shortness of breath & $16^{*}$ & 6.9 & 16 & $9 \cdot 8$ \\
\hline Cough & $62^{* *}$ & $32 \cdot 5$ & $66^{* *}$ & $43 \cdot 7$ \\
\hline Eczema & NA & NA & 40 & NA \\
\hline Hay fever & NA & NA & 24 & NA \\
\hline Morning symptoms & $40^{* *}$ & $22 \cdot 7$ & 40 & 28 \\
\hline Nocturnal symptoms & $48 * * *$ & $22 \cdot 4$ & $52^{*}$ & 34 \\
\hline $\begin{array}{l}\text { symproms induced by } \\
\text { exercise }\end{array}$ & 34 & $35 \cdot 7$ & NA & NA \\
\hline
\end{tabular}

$\left.{ }^{*} \mathrm{p}<(0) \cdot(1),{ }^{*} \mathrm{p}<(0) \cdot(0),{ }^{* * *} \mathrm{p}<0\right) \cdot(0) 1$, by $\chi^{2}$ test with Yates's correction $\mathrm{NA}=\mathrm{Not}$ assessed. 
been given a diagnosis of asthma by their general practitioner. Current and cumulative prevalences of symptoms of asthma together with eczema and hay fever are displayed in Table 2 and compared with data from the Southampton general population survey. All prevalence figures for respiratory symptoms, both current and cumulative, were one and a half to two times greater in the cohort children except for symptoms produced by exercise, chemicals, fumes, or smoke. The difference in prevalence of wheeze just failed to reach significance at the $5 \%$ level. The $95 \%$ confidence interval for the difference between the prevalence of wheeze in the cohort and the prevalence of wheeze in the general population $=+24 \cdot 4 \%$ to $-4 \cdot 2 \%$. The prevalences of eczema, $40 \%$, and hay fever, $24 \%$, were also high in the cohort.

The prevalence of symptoms in response to such provoking agents as chemicals, fumes, smoke, cold air, or exercise was similar between the cohort and the general population (Table 2). No child in the

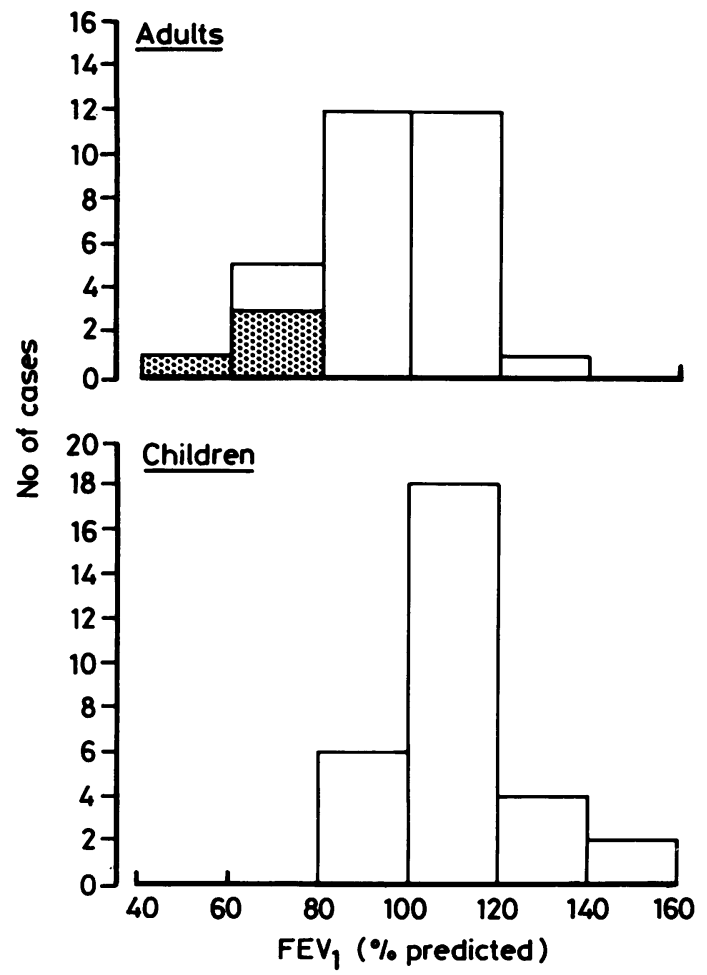

Fig. 1 Distribution of measurements of forced expiratory volume in one second $\left(F E V_{l}\right)$ in adults with asthma compared with their children. Shaded area represents subjects not tested for response to methacholine as $F E V_{1}<75 \%$ predicted. cohort group, however, had symptoms only in response to these provoking stimuli, which compares with $20 \%$ in the general population. Thirty three $(66 \%)$ of the 50 children had experienced breathlessness, wheeze, or problematic cough during the preceding 12 months, which compares with an expected figure of 18 subjects. Cough as the only symptom occurred with twice the prevalence in the cohort compared with the general population.

Respiratory function tests. Of 32 adults and children attending for testing, the $\mathrm{FEV}_{1}$ was satisfactorily recorded in 31 adults and 30 children (Fig. 1). $\mathrm{PD}_{20}$ for methacholine was measured in 28 adults and 29 children (Fig. 2). The mean per cent predicted FEV in the parent group was $92 \%$ and in the children $113 \%$. No parent or child with a $\mathrm{FEV}_{1}$ below $75 \%$ expected underwent methacholine provocation. Twenty six $(93 \%)$ parents were found to have a $\mathrm{PD}_{20}$ of $<6.4 \mu \mathrm{mol}$. Thirteen $(45 \%)$ children had a $\mathrm{PD}_{20}$ of $<6.4 \mu \mathrm{mol}$, which compares with $29.4 \%$ in

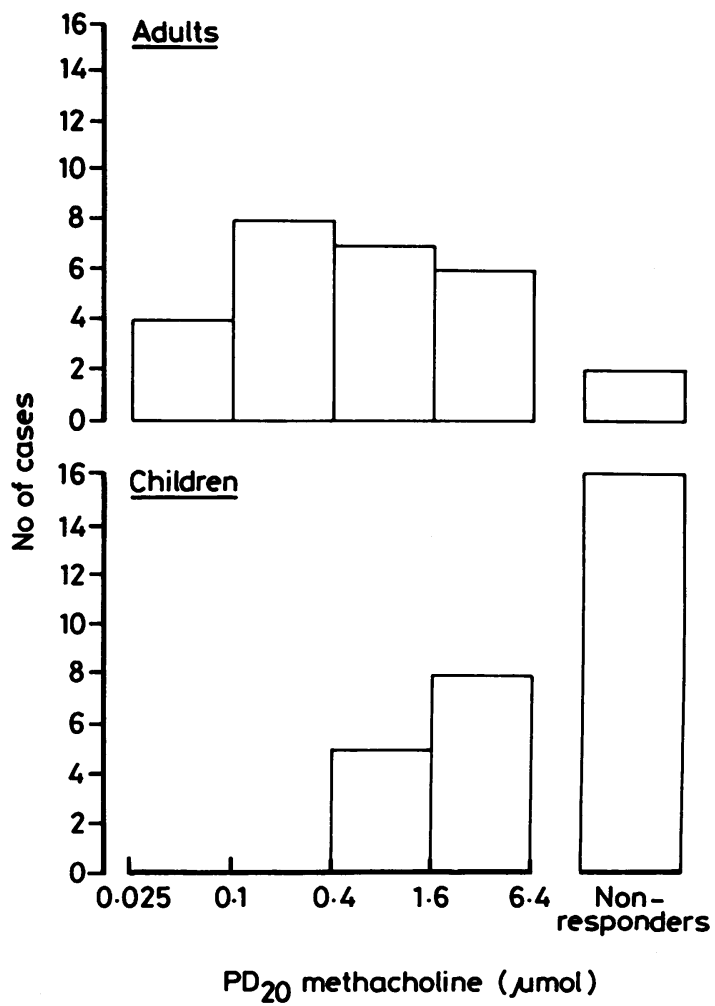

Fig. 2 Distribution of cumulative provocation dose of methacholine to cause a $20 \%$ fall in forced expiratory volume in one second ( $P D_{20}$ methacholine) among adults with asthma and their children. 
general population at 7 years calculated from the schools survey. This difference did not reach significance. The $95 \%$ confidence interval was calculated as: proportion in cohort responding to $<6.4 \mu \mathrm{mol}$ methacholine-proportion in general population responding to $<6.4 \mu \mathrm{mol}$ methacholine $=+34.9 \%$ to $-4 \%$. The distribution of responsiveness was broader in the adults than in the children and no child had a $\mathrm{PD}_{20}$ of less than $0.4 \mu \mathrm{mol}$ compared with 12 adults (43\%) (Fig. 2).

Skin tests. The results of the skin prick allergen tests are displayed in the form of a Venn diagram in Figure 3. All 32 adults and children were successfully tested. Twenty eight $(88 \%)$ parents were atopic (one or more positive skin tests). Just six $(19 \%)$ children in the cohort, however, were shown to be atopic compared with an expected prevalence of $24.5 \%$ at 7 years calculated from the schools survey. The $95 \%$ confidence limits for the difference was: prevalence of atopy in the cohort-prevalence of atopy in general population $=+9 \cdot 8 \%$ to $-20 \cdot 8 \%$. Hence there was only a 0.025 probability of a $10 \%$ or greater increased prevalence of atopy in children with one parent with asthma at this age. Ten parents but no children were positive to all three allergens. There were no cases in either the children or the parents where cat dander was the only positive test.

Relations between symptoms and objective testing. The combined data from the symptom questionnaire, skin allergen tests, and methacholine bronchial provocation are displayed in the form of a Venn diagram in Figure 4. For the purposes of this diagram a child who had any of the current respiratory symptoms listed in Table 2 has been classed as symptomatic. Parents have been classed as symptomatic if they had any of the current symptoms of bronchial irritability listed in Table 1 .
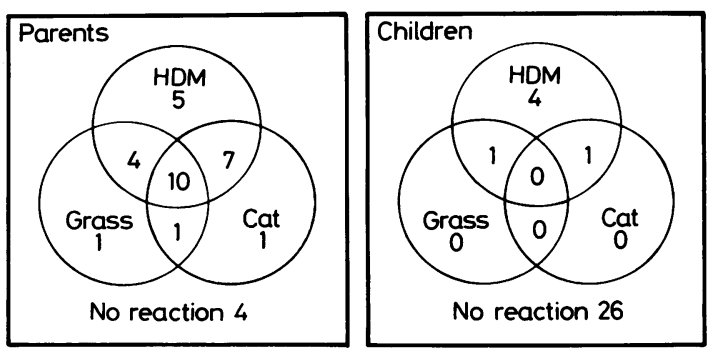

Fig. 3 Venn diagram representing the results of skin prick testing to house dust mite (HDM), mixed grass pollen (Grass), and cat fur (Cat) allergen extracts in adults with asthma and their children.
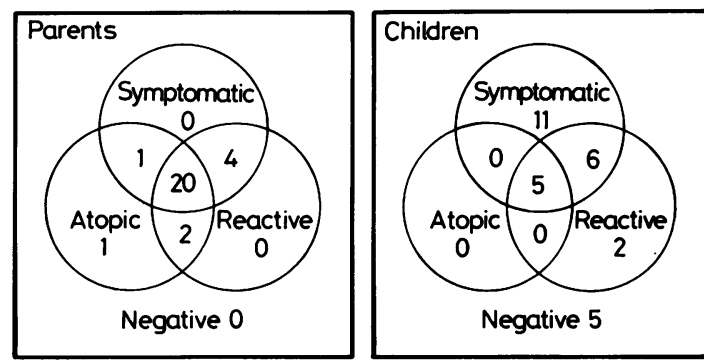

Fig. 4 Relation between symptoms, atopy, and bronchial responsiveness to methacholine (reactive) in adults with asthma and their children.

All symptoms were current. Twenty five of 28 parents tested for bronchial responsiveness to methacholine and atopy answered positively to these questions, and of these, $24(96 \%)$ responded to methacholine. Two parents who denied symptoms of bronchial irritability and who were both atopic responded to methacholine. In the children no significant association was found between any one respiratory symptom, or combination of symptoms, and methacholine bronchial responsiveness. Of 16 children who failed to respond to any dose of methacholine, 11 had one or more of the symptoms listed in Table 2, including wheeze or shortness of breath (five cases). Two children who had none of these symptoms were responsive to methacholine, although in both cases this was to the last dose given $(6.4 \mu \mathrm{mol})$.

In the children there was a significant relation between methacholine bronchial responsiveness and atopy $(p=0 \cdot 002$, Fisher's exact test). Five of six atopic children had bronchial provocation tests. All five were responsive to methacholine and had symptoms. A further six children who had symptoms and a positive methacholine provocation test were not atopic. None of the 11 symptomatic children who failed to respond to methacholine were atopic. The two asymptomatic children, who were responsive to methacholine, were both atopic. The remaining five children were unresponsive to methacholine, not atopic, and asymptomatic.

\section{Discussion}

Symptom quesionnaire. This study showed higher prevalences of respiratory symptoms in a cohort of children with one parent with asthma than in the general population survey of children of similar age conducted in Southampton during the same 12 months. The current prevalences of wheeze $(22 \%)$, shortness of breath $(16 \%)$, and cough $(62 \%)$ were 
all about double that in the general population. Using similar questions, the child health and education survey has shown overall prevalences of $12.2 \%$ and $4.2 \%$ for reported eczema and hay fever using a health visitor administered questionnaire. ${ }^{22}$ We have shown threefold and sixfold prevalences of these complaints in our cohort. This shows a considerable increase in the occurrence of allergic illness in children who have one parent with asthma.

Asthma has a high prevalence in adults and children. The general population data inevitably included many children with a family history of asthma. Thus exclusion of such children from these control data would have further increased the differences shown in this study. The mean age of the cohort $(6.4$ years) and the children in the schools survey ( $7 \cdot 4$ years) was slightly different, raising the possibility that some of the differences may have been age related. In the schools study we showed that the prevalences of wheeze and shortness of breath were similar at 7 and 11 years but that a fall in the prevalence of cough from $32.5 \%$ to $21 \%$ occurred. ${ }^{15}$ In view of the differences in only some symptoms during the four year interval between 7 years and 11 years, however, it seems unlikely that a one year interval would have significantly altered these data.

Bronchial response to methacholine. In the cohort $45 \%$ of children responded to a dose of $6.4 \mu \mathrm{mol}$ or less of methacholine compared with an expected figure of $28.9 \%$ from the schools survey. Although this difference just failed to reach significance at the $5 \%$ level, the $95 \%$ confidence intervals show that this result is consistent with a large increase in methacholine responsiveness between the cohort and general population in line with the higher prevalences of respiratory symptoms.

Atopy. In the present cohort of children aged between 5.3 and 7.3 years the prevalence of positivity to one or more of the three allergens tested was $19 \%$. The difference between this and the calculated population prevalence of $25 \cdot 5 \%$ is surprising but not significant. Calculation of the $95 \%$ confidence intervals shows that a $>10 \%$ increase in the prevalence of atopy in this age group in children with one parent with asthma is unlikely. None of the 34 parents and children found to be atopic among our subjects was negative to both house dust mite and grass pollen. Thus the use of the cat dander extract failed to identify any further atopic subjects.

Relations between symptoms, atopy, and bronchial responsiveness. In this cohort all five children who were both symptomatic and atopic responded to doses of less than $6.4 \mu \mathrm{mol}$ methacholine. Two thirds of the non-atopic children failed to respond, although a high proportion $(69 \%)$ had symptoms suggestive of asthma (Fig. 4). In this latter group increased responsiveness of the airways may only become manifest after a viral upper respiratory tract infection. ${ }^{23}$ Gregg has suggested that the age related improvement in respiratory symptoms in many children with wheezing induced by viral infections may occur as a result of spontaneous improvement in specific lower respiratory tract defence mechanisms together with acquisition of immunity to a progressively greater number of respiratory viruses. ${ }^{24}$ If atopy should later develop continued exposure to at least one allergen such as house dust mite faecal antigens could provide a persistent stimulus, resulting in the acquisition of a more permanent state of non-specific bronchial responsiveness detectable on formal testing. Platts-Mills has shown that enhanced bronchial responsiveness associated with symptoms of asthma may decrease substantially in a controlled dust free environment. ${ }^{11}$ Apart from such artificial situations, however, dust mite allergy results in almost inevitable daily allergen challenge. Thus we are able to propose a model that might explain the relation between classical asthma and 'wheezy bronchitis', a diagnosis over which there is much confusion. The consistent presence of methacholine bronchial responsivenes in the atopic children in our cohort compared with its absence in 11 of 17 symptomatic children who were not atopic is further support for this suggestion.

Whereas we have shown high prevalences of symptoms in this cohort, many of these children experienced cough as their only symptom. Out of cough, wheeze, and shortness of breath, only wheeze showed a non-significant increase from the general population prevalence $(0 \cdot 05<\mathrm{p}<0 \cdot 1)$, while cough was highly significant $(p<0.01)$. Many of these children suffered from nocturnal cough, which overall was the most common cause of nocturnal symptoms. The increased prevalence of nocturnal symptoms in the cohort was again highly significant $(\mathrm{p}<0.001)$.

The greater prevalence of cough alone compared with the general population suggests a specific disease: one fifth of schoolchildren with no other respiratory symptoms are considered by their parents, however, to have problematic cough (Table $3)$. Nevertheless, cough as the single presenting feature of asthma is now a well recognised occurrence. Many children with intermittent symptoms of asthma triggered by viral upper respiratory tract infections do not wheeze as their major symptom 
Table 3 Distribution of 50 children in the cohort among seven symptom groups compared with 1162 children from a general population sample

\begin{tabular}{lll}
\hline Symptom classification & $\begin{array}{l}\text { Cohort } \\
(\%)\end{array}$ & $\begin{array}{l}\text { Control } \\
(\%)\end{array}$ \\
\hline No current symptoms or past wheeze/ & 34 & 43 \\
$\quad$ shortness of breath & $40^{*}$ & $20 \cdot 7$ \\
Cough alone & 10 & $7 \cdot 2$ \\
Wheeze and/or cough & 4 & 1.9 \\
Shortness of breath and/or cough & 12 & $5 \cdot 7$ \\
Wheeze and shortness of breath and/or cough & & $20 \cdot 0$ \\
Symptoms only induced by exercise, fumes, & $00^{* *}$ & 1.5 \\
$\quad$ Wheke. or cold air \\
$\quad$ current symptoms
\end{tabular}

${ }^{*} \mathrm{p}<0.01,{ }^{* *} \mathrm{p}<0.001$, by $\chi^{2}$ test with Yates's correction.

but are more troubled by cough, particularly at night. In such children serial peak flow recordings, tests of reversibility of airways obstruction, and non-specific bronchial provocation may all be useful investigations before a trial of treatment is attempted; these procedures are still unavailable, however, in the absence of sophisticated equipment for very young children. Moreover, recent evidence suggests that such investigations are fallible as many children with clear symptoms of asthma do not show bronchial responsiveness to methacholine. ${ }^{2}$

In our general population study we have shown that these non-responders are mainly confined to the non-atopic group. Ninety three per cent of atopic children with wheeze respond to methacholine against just $17 \%$ of non-atopic children. Despite the high prevalence of symptoms of asthma in the cohort, we were unable to show a significant difference in the prevalence of methacholine responsiveness compared with the general population. This is partly due to the small number of atopic children among those tested. The increased tendency to allergic illness in these children is shown by the high prevalences of eczema and hay fever, suggesting that skin and pulmonary sensitivity to inhaled allergens may develop at a later date. A future study of the prevalence of bronchial responsiveness to methacholine in this cohort when the children are older would be interesting and may yield different results.

In conclusion, this study has shown that children with one parent with asthma, when compared with a recent general population study in schoolchildren, have roughly twofold prevalences of wheeze, shortness of breath, and cough with one and half times the prevalence of non-specific bronchial hyperresponsiveness of objective measurement. High prevalences of eczema and hay fever but not atopy were also shown. We were able to establish a close relation between non-specific bronchial hyperresponsiveness and the presence of atopy, suggesting a causal interaction.

We thank Mr F Anderson for performing all the bronchial provocation tests on the adult subjects and $\mathrm{Dr}$ M Campbell for statistical advice.

\section{References}

1 Gregg I. Epidemiological aspects. In: Clark T, Godfrey S, eds. Asthma. 2nd ed. London: Chapman and Hall, 1983;242-78.

2 Lee DA, Winslow NR, Speight ANP, Hey EN. Prevalence and spectrum of asthma in childhood. Br Med $J$ 1983;286:1256-8.

3 Anderson HR, Bailey PA, Cooper JS, Palmer JC, West S. Morbidity and school absence caused by asthma and wheezing illness. Arch Dis Child 1983;58:777-84.

${ }^{4}$ CIBA Foundation study group no 38. The identification of asthma. Edinburgh: Churchill Livingstone, 1971.

${ }^{5}$ Cockcroft DW, Killian DN, Mellon JJ, Hargreave FE. Bronchial reactivity to inhaled histamine: a method and clinical survey. Clin Allergy 1977;7:235-43.

- Chatham M, Eugene R, Bleecher R, et al. A comparison of histamine, methacholine, exercise airway reactivity in normal and asthmatic subjects. Am Rev Respir Dis 1982;126:235-40.

7 Deal EC, McFadden ER, Ingram JR, Breslin FJ, Jaeger JJ. Airway responsiveness to cold air and hyperpnea in normal subjects and in those with hay fever and asthma. Am Rev Respir Dis 1980;121:621-8.

${ }^{8}$ McFadden ER. Pathogenesis of asthma. J Allergy Clin Immunol 1984;73:413-24.

9 Sibbald B, Horn MEC, Brain EA, Gregg I. Genetic factors in childhood asthma. Thorax 1980;35:671-4.

${ }^{10}$ Cockcroft DW, Ruffin PE, Dolovich J, Hargreave FE. Allergen induced increase in non-allergic bronchial reactivity. Clin Allergy 1977;7:503-13.

1 Platts-Mills T, Tovey E, Mitchell B, Mozarro H, Noch P, Williams S. Reversal of bronchial hyperreactivity during prolonged allergen avoidance. Lancet 1982;ii:675-8.

12 Sibbald B, Turner-Warwick M. Factors influencing the prevalence of asthma among first degree relatives of extrinsic and intrinsic asthmatics. Thorax 1979;34:332-7.

${ }^{13}$ Edfors-Lubs M. Allergy in 7000 twin pairs. Acta Allergologica 1971;26:249-85.

14 Ogilvie M, Vathenen A, Radford M, Codd J, Key S. Maternal antibody and respiratory syncitial virus infection in infancy. $J$ Med Virol 1981;7:263-71.

15 Clifford RD, Holgate ST, Radford M. The symptoms of bronchial hyperresponsiveness in schoolchildren. Thorax 1986; 41:735.

${ }^{16}$ Mortagy A. Respiratory symptoms and bronchial reactivity: studies on their prevalence and clinical significance. Southampton: University of Southampton, 1984. (PhD Thesis.)

17 Yan K, Salome C, Woolcock AJ. Rapid method for measurement of bronchial responsiveness. Thorax 1983;38:760-5.

18 Woolcock AJ, Yan K, Salome C. Methods for assessing bronchial reactivity. Eur J Respir Dis 1983;64(suppl 128): 181-94.

${ }^{19}$ Britton J, Mortagy A, Tattersfield A. Histamine challenge testing: comparison of three methods. Thorax 1986;41:128-32.

20) Nie N, Hull H, Jenkin J, Steinbrenner K, Brent D. SPSS statistical package for social sciences. 2nd ed. New York: McGraw-Hill, 1975.

${ }^{21}$ Gardner MJ, Altman DG. Confidence intervals rather than $p$ 
values: estimation rather than hypothesis testing. $\mathrm{Br} \mathrm{Med} \mathrm{J}$ 1986;292:746-50.

22 Taylor B, Wadsworth J, Golding J, Butler N. Breast feeding, eczema, asthma and hayfever. $J$ Epidemiol Community Health 1983;37:95-9.

${ }^{23}$ Empey DW, Laitinen LA, Jacobs L, Gold WM, Nadel JA. Mechanisms of bronchial hyperreactivity in normal subjects after upper respiratory tract infection. Am Rev Respir Dis 1976;113:131-9.
${ }^{24}$ Gregg I. The role of infection. In: Clark T, Godfrey S, eds. Asthma. 2nd ed. London: Chapman and Hall, 1983;160-83.

Correspondence to Dr R D Clifford, Medicine 1, Level D, Centre Block, Southampton General Hospital, Tremona Road, Southampton S09 4XY, England.

Received 9 September 1986 